\title{
The Methionyl Transfer RNAs of Rous Sarcoma Virus
}

\author{
ANTHONY J. FARAS \\ Department of Microbiology, University of Michigan Medical School, Ann Arbor, Michigan 48104
}

Accepted October 12, 1974

\begin{abstract}
Virions of Rous sarcoma virus contain the two major classes of methionyl tRNA present in uninfected chick embryo fibroblasts. The formylated species, $N$-formyl methionyl tRNA, appears to be selectively associated with the viral $70 \mathrm{~S}$ RNA genome.
\end{abstract}

Virions of avian RNA tumor viruses contain several species of potentially functional transfer RNA(tRNA) which are thought to be selectively incorporated into virus particles during maturation of the virus by the process of budding from the cell membrane $(1-10)$. Although the bulk of this tRNA is found free in the virion, several of these species are complexed to the $70 \mathrm{~S}$ RNA genome (70 S-associated [70 S-a]tRNA) (10-14). One of the most prevalent tRNA species identified within virions of avian RNA tumor viruses is methionyl tRNA $(8,9,15)$. Recently, it has been demonstrated that virions of avian myeloblastosis virus (AMV) selectively incorporate certain isoaccepting species of methionyl tRNA and that quantitative differences in these isoaccepting species can be observed between the free and $70 \mathrm{~S}$ associated populations of methionyl tRNA $(16,17)$. In view of these results and the unique role of methionyl tRNA in the initiation of protein synthesis (18) we attempted to compare the methionyl tRNAs of avian sarcoma viruses with those from chick embryo fibroblasts in an effort to detect differences and/or similarities between a transforming oncornavirus and its host cell.

In this communication we present data indicating that all four of the isoaccepting species of methionyl tRNA present in chick embryo fibroblasts can be identified in virions of Rous sarcoma virus (RSV) and Rous-associated virus (RAV)-2, although substantial quantitative differences in certain isoaccepting species can be detected between the virus and the cell. These results confirm and extend previously published data obtained with two avian leukosis viruses, AMV and RAV-1 $(8,9,16)$. In addition, we present data suggesting that quantitative differences exist between the $70 \mathrm{~S}$-a and free methionyl tRNA isoaccepting species in both RSV and RAV-2, a result similar to the data recently published by Elder and Smith with AMV (17).

The B77 (subgroup C), Schmidt-Ruppin (subgroup A), and Prague C (subgroup C) strains of RSV were propagated in chick embryo fibroblasts as described previously (19). Virus was purified by precipitation from tissue culture fluids with ammonium sulfate, followed by sedimentation through $15 \%(\mathrm{w} / \mathrm{v})$ sucrose to a cushion of $40 \%(\mathrm{w} / \mathrm{v})$ potassium tartrate and banding in $25-65 \%$ sucrose. Viral RNA was extracted with sodium dodecyl-sulfate(SDS)-phenol at room temperature and $70 \mathrm{~S}$ RNA was fractionated from the free low-molecularweight RNAs by rate-zonal sedimentation in $15-30 \%$ sucrose in an SW 41 rotor at $40,000 \mathrm{rpm}$ for $3 \mathrm{hr}$ at $4^{\circ}(20)$. The $70 \mathrm{~S}-\mathrm{a}$ RNA was obtained by denaturing $70 \mathrm{~S}$ RNA with $90 \%$ dimethylsulfoxide (DMSO) for $30 \mathrm{~min}$ at $37^{\circ}$ and fractionating the resultant $70 \mathrm{~S}-\mathrm{a} 4 \mathrm{~S}$ RNA from the $35 \mathrm{~S}$ RNA by rate-zonal sedimentation in an $\mathrm{SW} 41$ rotor at $29,000 \mathrm{rpm}$ for $16 \mathrm{hr}$ at $4^{\circ}$. The free, low-molecular-weight RNA was subjected to $1 \mathrm{M} \mathrm{NaCl}$ fractionation (21)

Copyright (c) 1975 by Academic Press, Inc.

All rights of reproduction in any form reserved. 
and then treated with $10 \mu \mathrm{g} / \mathrm{ml}$ of RNasefree DNase, prepared as described in Faras et al. (22), for $1 \mathrm{hr}$ at room temperature in $0.01 M$ Tris- $\mathrm{HCl}, \mathrm{pH} 7.4,0.01 \mathrm{M} \mathrm{MgCl}_{2}$ to remove any residual DNA that may be present in the $4 \mathrm{~S}$ RNA preparations.

Total cellular RNA was extracted with phenol at $60^{\circ}$ in $0.05 \mathrm{M}$ sodium acetate, $0.01 M$ EDTA, pH 5.0. The $4 S$ RNA was separated from ribosomal RNA by ratezonal sedimentation as described above for $70 \mathrm{~S}-\mathrm{a} 4 \mathrm{~S}$ RNA, and subjected to $1 \mathrm{M}$ $\mathrm{NaCl}$ fractionation and DNase treatment as described in the preceding paragraph. Deacylation was accomplished by treat- ment with $0.1 M$ Tris- $\mathrm{HCl}, \mathrm{pH} 8.1$, for $1 \mathrm{hr}$ at $37^{\circ}$.

Aminoacyl-tRNA synthetases were prepared from homogenates of chick embryos as described by Erikson and Erikson (5). One preparation was a gift from B. CordellStewart of the University of California, San Francisco. In vitro acylation of tRNAs with labeled methionine $\left(\left[{ }^{35} \mathrm{~S}\right]\right.$ methionine, $209 \mathrm{Ci} / \mathrm{mmole}$, New England Nuclear) was performed in reaction mixtures containing $100 \mathrm{~m} M$ Tris- $\mathrm{HCl}, \mathrm{pH} 7.4,10 \mathrm{mM} \mathrm{KCl}, 10$ $\mathrm{m} M \mathrm{MgCl}_{2}, 6 \mathrm{~m} M$ CTP, $10 \mathrm{~m} M$ ATP, 6 $\mathrm{m} M$ 2-mercaptoethanol, and 100-200 $\mu \mathrm{g} / \mathrm{ml}$ of synthetase protein and were incu-

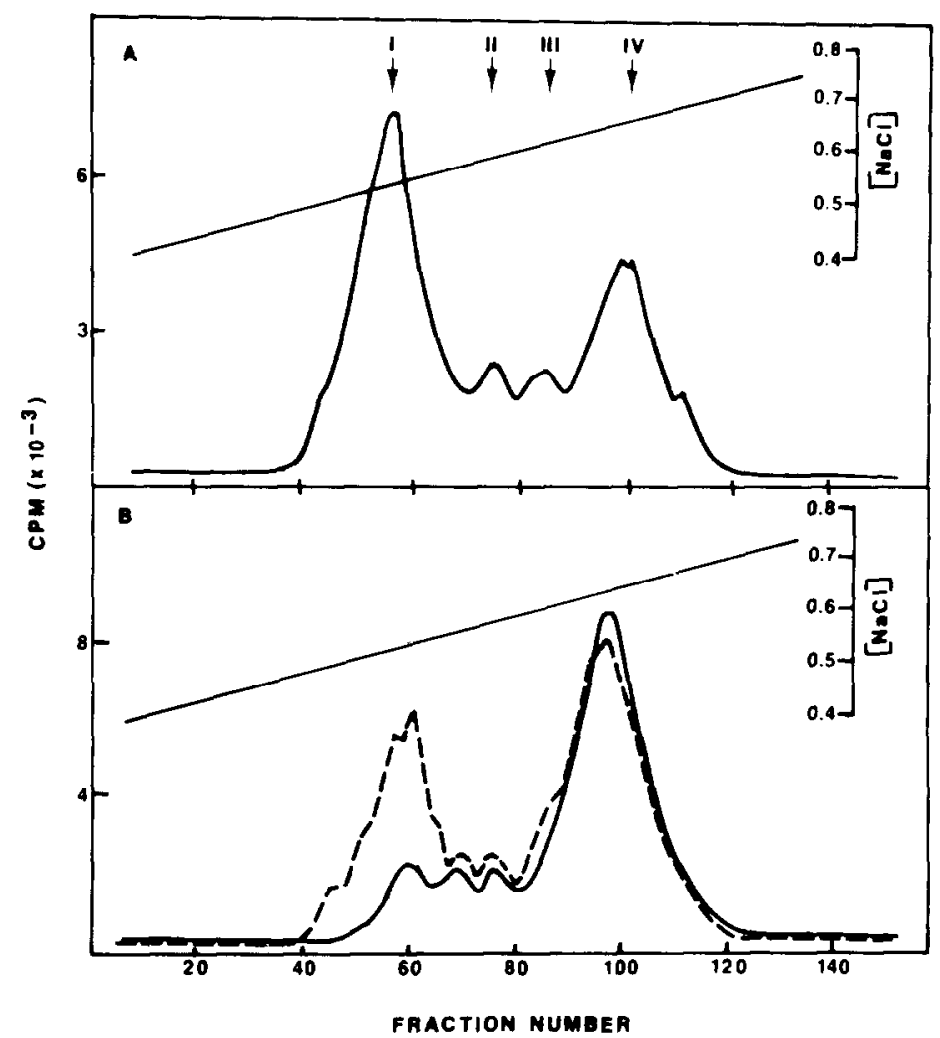

FIG. 1. RPC-5 chromatography of methionyl tRNA from Rous sarcoma virus. RSV and chick embryo fibroblast tRNA, aminoacylated with ${ }^{38} \mathrm{~S}$-labeled methionine, was applied to a $0.9 \times 25 \cdot \mathrm{cm}$ column of RPC-5 (Miles Laboratories). The isoaccepting species were eluted from the column with a 140-ml linear gradient of $0.45-0.7 M \mathrm{NaCl}$ containing $10 \mathrm{~m} M$ sodium acetate, $\mathrm{pH} 4.5,10 \mathrm{mM} \mathrm{MgCl}_{2}$, and $2 \mathrm{mM}$ 2-mercaptoethanol at a flow rate of $16 \mathrm{ml} / \mathrm{hr}$ at room temperature. Fractions were precipitated with $10 \%$ TCA, collected onto glass fiber filters and counted in a Beckman liquid scintillation spectrometer. Recovery from RPC-5 was routinely greater than $70 \%$. The profile of methionyl tRNA from chick embryo fibroblasts is presented in panel A. Panel B represents a composite of two separate chromatographic analyses of RSV free (solid line) and $70 \mathrm{~S}-\mathrm{a}$ methionyl tRNA (broken line). The data presented was obtained with the B77 strain of RSV; however, similar profiles were obtained with both the Schmidt-Ruppin and Prague C strains of RSV. 
bated for $20 \mathrm{~min}$ at $37^{\circ}$. Aminoacylated tRNA was extracted from the reaction mixtures with $0.01 M$ sodium acetate $(\mathrm{pH}$ 4.3)-phenol at room temperature.

Crude preparations of transformylase were prepared by centrifuging disrupted preparations of $E$. coli B at $10,000 \mathrm{rpm}$ for $15 \mathrm{~min}$ and then subjecting the supernatant fraction to $\left(\mathrm{NH}_{6}\right)_{2} \mathrm{SO}_{4}$ precipitation $(50 \%)$. Conditions for transformylation are described in the legend to Fig. 3.

The methionyl-containing tRNAs from chick embryo fibroblasts can be resolved into four major peaks when subjected to RPC-5 chromatography (Fig. 1A). Similarly, all four isoaccepting methionyl tRNA species can be identified in virions of RSV, both free and associated with the 70 S RNA complex (Fig. 1B). As is the case for AMV (17), significant quantitative differences can be demonstrated between the isoaccepting species of free and $70 \mathrm{~S}$-a populations of methionyl tRNA. Whereas the free population of RSV methionyl tRNA contains low amounts of peaks I, II, and III relative to peak IV, methionyl tRNA obtained from $70 \mathrm{~S}$ RNA appears to contain appreciably more peak I relative to peak IV and is, therefore, more representative of the methionyl tRNA obtained from chick embryo fibroblasts. Profiles both qualitatively and quantitatively similar to RSV are observed with the free and $70 \mathrm{~S}-\mathrm{a}$ methionyl tRNAs of RAV-2, indicating a similar distribution of methionyl tRNAs exists within virions of nontransforming viruses (Faras, A., unpublished observations).

Chromatography of eukaryotic methionyl tRNA on benzoylated DEAE-cellulose (BD-cellulose) resolves the tRNA into two discrete classes (18). One of these classes can be formylated by the $E$. coli transformylase and appears to be the initiator tRNA, $N$-formyl methionyl tRNA (tRNA ${ }_{\mathrm{f}}^{\text {met }}$ ) species (18). The other does not accept formyl groups and is, therefore, a methionyl tRNA (tRNA ${ }^{\text {met}}$ ) species (18). We subjected the methionyl tRNAs of RSV to chromatography on BD-cellulose in an effort to determine if both classes of this tRNA species are associated with these viruses. Both the $70 \mathrm{~S}-\mathrm{a}$ (Fig. 2) and free methionyl tRNA's (data not shown) can be resolved into two discrete peaks by this procedure suggesting that RSV contains both methionyl and $N$-formyl methionyl tRNA species.

More direct evidence that both of these classes of methionyl tRNA are present in virions of RSV was obtained by analysis of the amino acid acceptor ends of these species. Since the amino acid acceptor ends of these two classes of eukaryotic methionyl tRNAs contain different nucleotide sequences, they can be readily distin-

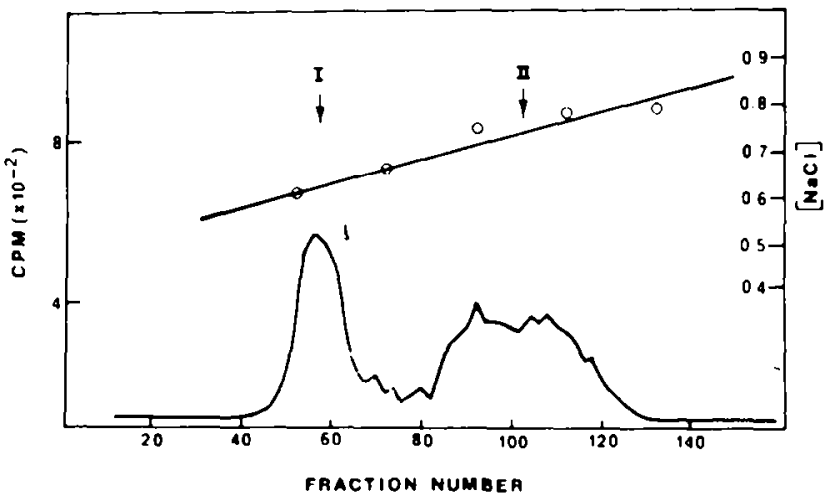

Fig. 2. Benzoylated DEAE-cellulose chromatography of RSV 70 S-associated methionyl-tRNA. Acylated 70 S-associated "S-labeled methionyl tRNA was applied to a $0.9 \times 13-\mathrm{cm}$ column of benzoylated DEAE-cellulose (Schwarz-Mann) and eluted with a $400-\mathrm{ml}$ gradient of $0.45-0.9 \mathrm{M} \mathrm{NaCl}$ in $10 \mathrm{mM}$ sodium acetate, pH 4.5, 10 $\mathrm{mM} \mathrm{MgCl}$, and $1 \mathrm{mM}$ 2-mercaptoethanol at a flow rate of $8 \mathrm{ml} / \mathrm{hr}$ at room temperature. Fractions were assayed as in Fig. 1. Recoveries from BD-cellulose were greater than $75 \%$. 


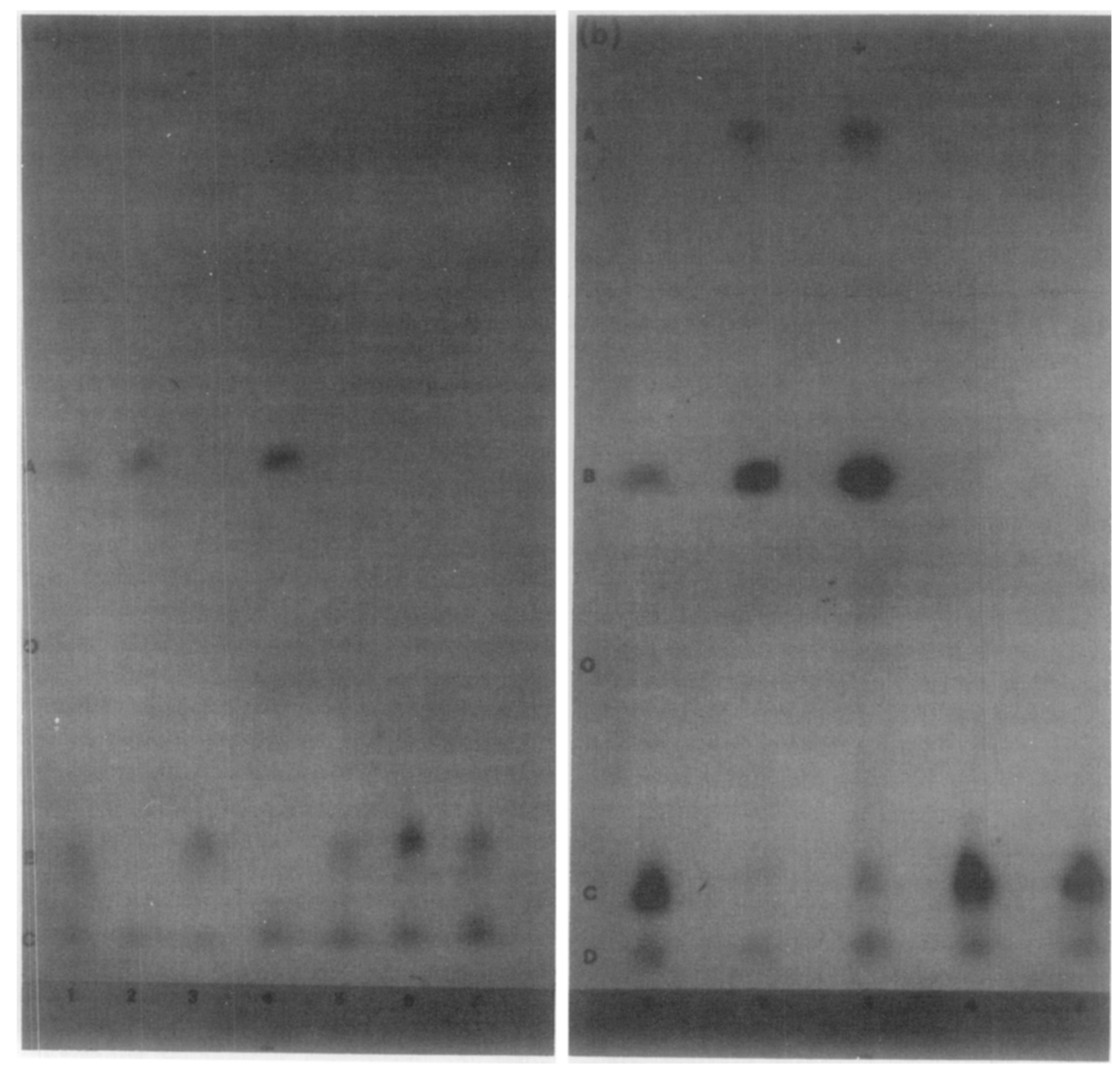

FIG. 3. Transformylation of RSV methionyl-tRNA. Isoaccepting species of ${ }^{\text {ss }} \mathrm{S}$-labeled methionyl-tRNA were obtained by chromatography on RPC-5 or benzoylated DEAE-cellulose as described in Figs. 1 and 2 , respectively. (a) The various isoaccepting species of methionyl-tRNA were treated with $100 \mu \mathrm{g} / \mathrm{ml}$ of T1 RNase in $10 \mathrm{mM}$ sodium acetate buffer, $\mathrm{pH} 5.4$, containing $1 \mathrm{mM}$ EDTA and $20 \mu \mathrm{g}$ of carrier RNA for $15 \mathrm{~min}$ at $37^{\circ}$. The samples were directly applied to Whatman 3 MM paper, subjected to electrophoresis for $2.5 \mathrm{hr}$ at $50 \mathrm{~V} / \mathrm{cm}$, and autoradiographed with Kodak NS 54-T X-ray film. (1) Total chick embryo fibroblast ${ }^{35} \mathrm{~S}$-labeled methionyl tRNA, (2) peak I from BD-cellulose, (3) peak II from BD-cellulose, (4) peak I from RPC-5, (5) peak II from RPC-5, (6) peak III from RPC-5, (7) peak IV from RPC-5. (A) is the position of the T1 oligonucleotide obtained from $N$-formyl methionyl tRNA $(16,18) ;(B)$ is the position of the T1 oligonucleotide from methionyl tRNA (16, 18); (C) is the position of free methionine; and 0 , is the origin. (b) Transformylation of the isoaccepting tRNAs was performed with a crude preparation of transformylase obtained from $E$. coli as described in the text. The reaction conditions were essentially as described by Marcker and Sanger (27) and contained $100 \mathrm{mM} \mathrm{Tris}-\mathrm{HCl}$, pH 7.0, $10 \mathrm{mM} \mathrm{MgCl}, 40 \mathrm{mM}$ ammonium acetate, $5 \mathrm{mM}$ ATP, $400 \mu \mathrm{g} / \mathrm{ml}$ of crude transformylase protein and $200 \mu \mathrm{g} / \mathrm{ml}$ of leucovorin as the formyl donor (17). Incubation was for $15 \mathrm{~min}$ at $37^{\circ}$. Under these conditions the transformylation reaction was rarely complete, with generally only $25-40 \%$ of $\mathrm{tRNA} \mathbf{f}_{\mathrm{f}}^{\text {met }}$ becoming formylated. Increasing the incubation time resulted in somewhat more transformylation; however, considerable deacylation was also detected. Subsequent to incubation, the reaction mixtures were adjusted to $\mathrm{pH} 4.3$ with sodium acetate buffer, extracted twice at room temperature with phenol equilibrated with $0.01 M$ sodium acetate, $\mathrm{pH}$ 4.3, and ethanol precipitated. The samples were subjected to T1 RNase digestion as described above, applied to Whatman $3 \mathrm{MM}$ paper, electrophoresed at $\mathrm{pH} 3.5$ for $2.5 \mathrm{hr}$ at $50 \mathrm{~V} / \mathrm{cm}$ and autoradiographed. (1) is total chick embryo fibroblast methionyl-tRNA not subjected to transformylation, (2) is peak I from RPC-5, (3) is peak I from BD-cellulose, (4) is the pattern obtained if RPC-5 peaks II, III, or IV are subjected to transformylation (peak IV is presented), and, (5) is peak II from BD-cellulose. The oligonucleotide in position (A) is the formylated methionine-containing T1 oligonucleotide $(18,24)$; the oligonucleotide in position (B) is the T1 oligonucleotide from $N$-formyl methionyl tRNA; the oligonucleotide in position (C) is the T1 oligonucleotide from methionyl tRNA; position (D) represents free methionine; and 0 is the origin. 
guished from one another on the basis of their apparent differences in electrophoretic mobility (18). If methionyl tRNA peaks I and II, obtained from BD-cellulose, are treated with $\mathrm{T} 1 \mathrm{RNase}$ and subjected to electrophoresis at $\mathrm{pH} 3.5$, considerable differences in electrophoretic mobility of the methionyl-containing oligonucleotides can be demonstrated (Fig. $3 \mathrm{a}$ ). The relative positions of these oligonucleotides suggest that they are similar to oligonucleotides obtained from tRNA ${ }_{\mathrm{f}}^{\text {met }}$ and tRNA ${ }^{\text {met }}$ (18). A similar analysis of peaks I, II, III, and IV from RPC-5 reveals the presence of the methionyl-containing oligonucleotide obtained from $N$-formyl methionyl tRNA only in peak $I$, whereas the methionyloligonucleotide with an electrophoretic mobility similar to that obtained from tRNA $^{\text {met }}$ can be demonstrated in peaks II, III, and IV.

Since eukaryotic $\operatorname{tRNA}_{\mathrm{f}}{ }^{\text {met }}$ can be formylated by the $E$. coli transformylase (23), we subjected the four RPC-5 peaks and the two $\mathrm{BD}$-cellulose peaks to transformylation. Only peak I from either RPC-5 or BD-cellulose could be formylated by the $E$. coli transformylase as evidenced by the presence of the formylated methionyl-containing oligonucleotide that appears on the radioautograph subsequent to formylation (position A, Fig. 3b). BD-cellulose peak II and RPC-5 peaks II, III, and IV remain unaffected when exposed to transformylation conditions. Additional evidence that the oligonucleotide at position $\mathrm{A}$ in Fig. $3 \mathrm{~b}$ is a formylated methionyl oligonucleotide was obtained by eluting this oligonucleotide from the paper, treating it with pancreatic $R$ Nase, and subjecting the resultant product to electrophoresis on paper at pH 3.5 (data not shown). The oligonucleotide obtained from position A in Fig. 3b yields an $N$-formyl methionyl adenosine whereas the oligonucleotide obtained from position $B$ yields a methionyl adenosine residue subsequent to such treatment (17, 24).

We conclude that virions of RSV contain the two major classes of methionyl tRNA, tRNA $^{\text {met }}$, and tRNA ${ }_{\mathrm{f}}{ }^{\text {met }}$, found in their host cells. These two classes can be distin- guished from one another on the basis of their chromatographic behavior on RPC-5 and BD-cellulose, and their capacity, or lack thereof, to serve as substrate for the $E$. coli transformylase. A comparative analysis of methionyl tRNA from RSV and chick embryo fibroblasts suggests that avian sarcoma viruses selectively incorporate specific isoaccepting species of methionyl tRNA from their host cells similar to the avian leukosis viruses, RAV-1 and AMV (8, $9,16)$. Furthermore, it appears as if more tRNA $_{f}{ }^{\text {met }}$ is found associated with $70 \mathrm{~S}$ RNA than free in virions of RSV and RAV -2 suggesting a preferential association of the formylated methionyl tRNA species with the viral genome. Whether these methionyl tRNAs, selectively associated with the RSV genome, serve any function in the maintenance of the $70 \mathrm{~S}$ RNA complex or have any specific role at all in the life cycle of the avian RNA tumor viruses, remains to be elucidated. To date, only one of the dozen or so different tRNA species contained within virions of RSV, appears to participate in a viral-specific function. This particular species is utilized as a primer molecule in the initiation of RNA-directed DNA synthesis by the RSV RNA-directed DNA polymerase in vitro $(22,25,26)$. This tRNA-like primer molecule does not appear to chromatograph with any of the forms of RSV or cellular methionyl tRNA's identified in this communication (B. Cordell-Stewart, personal communication and A. Faras, unpublished observations).

\section{ACKNOWI,EDGMENTS}

I am indebted to N. Dibble and C. Fox for excellent technical assistance, and to Dr. R. Greenberg for helpful discussions on formylation and his generous gift of leucovorin. This study was supported by United States Public Health Service Grant CA 14790-01, from the National Cancer Institute and Grant DRG-1268 from the Damon Runyon Memorial Fund for Cancer Research.

\section{REFERENCES}

1. Bonar, R. A., Suerak, L., Bolognesi, D. P., Langlois, A. J., Beard, D., and Beard, J. W., Cancer Res. 27, 1138-1157 (1967).

2. Carnegie, J. W., Defenty, A. D., Olson, K. C., 
and Beaudreau, G. S., Biochim. Biophys. Acta 190, 274-284 (1969).

3. Traynicek, M., Biochim. Biophys. Acta 166, 757-759 (1968).

4. TravniceK, M., Biochim. Biophys. Acta 182, 427-439 (1969).

5. Erikson, E., and Erikson, R. L., J. Mol. Biol. 52, 387-390 (1970).

6. Bishop, J. M., Levinson, W. E., Quintrell, N., Sullivan, D., FanshiER, L. and JaCKSON, J., Virology 42, 182-195 (1970).

7. Randerath, K. L., Rosenthal, L. J., and ZamecNIK, P. C., Proc. Nat. Acad. Sci. USA 68, 3233-3237 (1971).

8. Wang, S., Kothari, R. M., Taylor, M., and Hung, P., Nature New Biol. 242, 133-135 (1973).

9. Gallagher, R. E., and Gallo, R. C., J. Virol. 12, 449-457 (1973).

10. Rosenthal, L. J., and Zamecnik, P. C., Proc. Nat. Acad. Sci. USA 70, 1184-1185 (1973).

11. Erikson, E., and Erikson, R. L., J. Virol. 8, 254-256 (1971).

12. Faras, A. J., Garapin, A. C., Levinson, W. E., Bishop, J. M., and Goodman, H. M., J. Virol. 12, 334-342 (1973).

13. Rosenthal, L. J., and Zamecnik, P. C., Proc. Nat. Acad. Sci. ISA 70, 865-869 (1973).

14. Sawyer, R. C., and Dahlberg, J. E., J. Virol. 12, 1226-1237 (1973).

15. Bishop, J. M., Deng, C. T., Faras, A., Goodman, H., Guntaka, R., Levinson, W., Cordell-
Stewart, B., Taylor, J., and Varmus, H., In "Proceedings of the Fourth International Symposium on Comparative Leukemia Research." S. Karger, New York, 1974.

16. Elder, K. T., and Smith, A. E., Proc. Nat. Acad. Sci. USA 70, 2823-2826 (1973).

17. EldER, K. T., and Smith, A. E., Nature (London) 247, 435-438 (1974).

18. SMITH, A. E., and Marcker, K. A., Nature (London) 226, 607-610 (1970).

19. Levinson, W., Virology 32, 74-83 (1967).

20. Faras, A. J., Taylor, J. M., McDonnell, J. P., Levinson, W. E., and Bishop, J. M., Biochemistry 11, 2334-2342 (1972).

21. Bishop, J. M., and Косн, G., J. Biol. Chem. 242, 1736-1741 (1967).

22. Faras, A. J., Taylor, J. M., Levinson, W. E., Goodman, H. M., and Bishop, J. M., J. Mol. Biol. 79, 163-183 (1973).

23. Caskey, C. T., Redfield, B., and Weissbach, H., Arch. Biochem. Biophys. 120, 119-123 (1967).

24. Marcker, K., J. Mol. Biol. 14, 63-70 (1965).

25. Dahlberg, J. E., Sawyer, R. C., Taylor, J. M., Faras, A. J., Levinson, W. E., Goodman, J. M., and Bishop, J. M., J. Virol. 13, 1126-1133 (1974).

26. Faras, A. J., Dahlberg, J. E., Sawyer, R. C., Harada, F., Taylor, J. M., Levinson, W. E., Bishop, J. M., and Goodman, H. M., J. Virol. 13, 1134-1142 (1974).

27. Marcker, K., and Sanger, F., J. Mol. Biol. 8, 835-840 (1964). 